\title{
Histopathological evaluation of endometrial sampling in perimenopausal women with abnormal uterine bleeding
}

\author{
Bhavani L. Nair, Lency S. Kuriakose*
}

Department of Obstetrics and Gynecology, Sree Gokulam Medical College and Research Foundation, Venjaramood, Thiruvananthapuram, Kerala, India

Received: 12 June 2021

Accepted: 07 July 2021

\section{*Correspondence:}

Dr. Lency S. Kuriakose,

E-mail: lencysk2@gmail.com

Copyright: (C) the author(s), publisher and licensee Medip Academy. This is an open-access article distributed under the terms of the Creative Commons Attribution Non-Commercial License, which permits unrestricted non-commercial use, distribution, and reproduction in any medium, provided the original work is properly cited.

\begin{abstract}
Background: Abnormal uterine bleeding (AUB) is one of the common symptoms in the gynaecology outpatient department. About one third of women are affected at some time in their lives. The perimenopausal women show significant number of underlying organic pathology. The evaluation of endometrium and/or organ histopathology has the dual advantage of finding the cause of AUB and to rule out endometrial cancer or the potential for cancer in future like endometrial hyperplasia with atypia. The aim of the study was to determine the histopathological pattern of endometrial sampling in perimenopausal women with AUB and to follow them up for a period of six months after the procedure.

Methods: The prospective observational study was conducted at the department of obstetrics and gynaecology at Sree Gokulam Medical College and Research Foundation, Venjaramood, Thiruvananthapuram, Kerala, for a period of one year from December 2019 to December 2020. The study was conducted on 116 perimenopausal women 41-52 years who presented with AUB and had undergone endometrial sampling. These ladies were subsequently followed up for six months post procedure to assess the response to medical treatment or the need for any surgical intervention like hysterectomy.

Results: A total $39.65 \%$ patients had heavy and prolonged menstrual bleeding and $18.16 \%$ patients had irregular bleeding. $14.65 \%$ patients had prolonged flow, $8.6 \%$ had heavy flow, $6.8 \%$ had infrequent with prolonged flow, $6 \%$ had prolonged, infrequent with heavy bleeding. Non-structural (COEIN) causes contributed to about $60.4 \%$ of AUB in perimenopausal women and $39.6 \%$ had structural (PALM) causes. $49 \%$ cases were secretory endometrium. $29.3 \%$ had disordered proliferative endometrium, $4.3 \%$ had proliferative endometrium, $5.2 \%$ each had polyp or hyperplasia without atypia. $18(15.5 \%)$ cases underwent hysterectomy, 3 patients who had adenocarcinoma underwent staging laparotomy, 2 patients had LNG IUS insertion and 40 patients were on follow up requiring either no treatment and $53(45.68 \%)$ patients were given antifibrinolytics or hormonal therapy.

Conclusions: Heavy and prolonged menstrual bleeding was the most common presenting symptom. COEIN contributed to about $60.4 \%$ of cases. Evaluation of the endometrium showed that, secretory endometrium was commonest (49\%) followed by disordered proliferative endometrium $(29.3 \%)$. On follow up for six months, $15.5 \%$ patients underwent hysterectomy, 2 patients had insertion of levonorgestrel IUD, $45.68 \%$ patients had medical management with antifibrinolytics or hormones and were on follow up. The responsibility of gynaecologist in the management of AUB in perimenopausal women is to exclude hyperplasia of endometrium and endometrial cancer.
\end{abstract}

Keywords: Perimenopausal AUB, Endometrial sampling, palm-coein

\section{INTRODUCTION}

Abnormal uterine bleeding (AUB) is one of the common symptoms in the gynaecology outpatient department. About one third of women are affected at sometime in their lives. It is estimated that approximately $30 \%$ of women 
complain of menorrhagia. Excessive bleeding is the main presenting complaint in women referred to gynecologist and it accounts for $2 / 3$ rd of all hysterectomies. ${ }^{1,2}$

Chronic non-gestational AUB in the reproductive years is defined as bleeding from uterine corpus that is abnormal in regularity, volume, frequency or duration and has been present for the majority of the preceding 6 months. Acute AUB is defined as an episode of heavy bleeding that, in the opinion of the clinician, is of sufficient quantity to require immediate intervention to minimise or prevent further blood loss. ${ }^{3}$
In the revised International Federation of Gynaecology and Obstetrics-Abnormal Uterine Bleeding (FIGO-AUB) system 1 in 2018, terms such as menorrhagia, metrorrhagia, oligomenorrhoea and dysfunctional uterine bleeding has been removed.

Definitions of the AUB symptoms are given in the Table $1 .^{3}$ Heavy menstrual bleeding is defined by National Institute of Clinical Excellence as excessive menstrual blood loss, which interferes with a woman's physical, social, emotional and/or material quality of life. ${ }^{4}$

Table 1: FIGO AUB system-1 nomenclature and definitions of AUB symptoms.

\begin{tabular}{|c|c|c|}
\hline Parameters & Normal & Abnormal \\
\hline \multirow{3}{*}{ Frequency } & \multirow{3}{*}{$>24-\leq 38$ days } & Frequent ( $<24$ days) \\
\hline & & Infrequent ( $>38$ days) \\
\hline & & Absent= amenorrhea \\
\hline Duration & $\leq 8$ days & Prolonged (>8 days) \\
\hline Regularity & $\begin{array}{l}\text { Regular (shortest to longest cycle } \\
\text { variation: } \leq 7-9 \text { days) }\end{array}$ & $\begin{array}{l}\text { Irregular (shortest to longest cycle } \\
\text { variation } \geq 8 \text { - } 10 \text { days) }\end{array}$ \\
\hline Flow volume & Normal & $\begin{array}{l}\text { Light } \\
\text { Heavy }\end{array}$ \\
\hline Intermenstrual bleeding & None & $\begin{array}{l}\text { Random } \\
\text { Cyclic-early cycle } \\
\text { Mid cycle } \\
\text { Late cycle }\end{array}$ \\
\hline $\begin{array}{l}\text { Unscheduled bleeding on progestin } \pm \\
\text { oestrogen gonadal steroids (birth } \\
\text { control pills, rings, patches or } \\
\text { injections) }\end{array}$ & $\begin{array}{l}\text { Not applicable (not on gonadal } \\
\text { steroid medication) } \\
\text { None (on gonadal steroid } \\
\text { medication) }\end{array}$ & Present \\
\hline
\end{tabular}

FIGO working group on menstrual disorders has developed classification system (PALM COEIN) for causes of AUB in non-gravid women in 2011 and was revised in 2018. The acronym PALM COEIN facilitates classification, with PALM referring to structural etiologies that can be imaged and/or defined histopathologically (polyp, adenomyosis, leiomyoma, malignancy or atypical endometrial hyperplasia), and COEIN referring to non-structural etiologies that cannot be imaged, but clinical assessment with detailed history and appropriate physical examination, sometimes supported by laboratory testing, can largely imply or make a diagnosis of cause (coagulopathy, ovulatory disorders, primary endometrial disorders, iatrogenic, not otherwise classified). ${ }^{3}$

Perimenopause is defined as period of two to eight years preceding menopause and one year after the final menses. ${ }^{5}$ Follicular development at this period is found to be erratic with increased percentage of anovulatory cycles. ${ }^{6}$

The perimenopausal women show significant number of underlying organic pathology. The responsibility of gynaecologist in the management of AUB in perimenopausal women is to exclude hyperplasia of endometrium and endometrial cancer. The evaluation of endometrium and/or organ histopathology has the dual advantage of finding the cause of AUB and to rule out endometrial cancer or the potential for cancer in future like endometrial hyperplasia with atypia.

Transvaginal ultrasonography (TVUS) is an appropriate and important screening tool and, in most instances, should be performed early in the course of the investigations. ${ }^{3}$ Transvaginal ultrasound is $80 \%$ sensitive and $69 \%$ specific for identifying submucous myomas and is superior to trans- abdominal ultrasound, $96 \%$ sensitivity and $86 \%$ specificity in diagnosis of intrauterine abnormality. ${ }^{7}$

FIGO recommends endometrial sampling as the first line management of perimenopausal women with AUB. Although some studies have indicated that age is not important as an independent variable, most suggest that endometrial sampling be considered for all women over a certain age, usually 45 years. ${ }^{8,9}$ Regardless of the clinical guideline, when AUB is persistent and either unexplained or inadequately treated, endometrial sampling is necessary- if possible- in association with hysteroscopic evaluation of the uterine cavity. ${ }^{4}$

Histology contributes to better understanding of mechanism of action that initiate, regulate and lead to AUB. Better insights may trigger the development of therapeutic procedures that would either prevent or control 
vascular breakdown which results in unexpected uterine bleeding. ${ }^{2}$

A blind Dilatation and Curettage $(\mathrm{D}$ and $\mathrm{C})$ is a procedure for all women with AUB in $>40$ years age group. In 10$25 \%$ of patients $\mathrm{D}$ and $\mathrm{C}$ may miss an existing endometrial pathology. Office endometrial biopsy results in adequate samples $87-97 \%$ time, and detects $67-96 \%$ of endometrial carcinomas. $^{10}$

Hysteroscopy allows direct visualization of the endometrial cavity and is combined with endometrial biopsy. Saline sonohysterogram involves introducing 5-15 $\mathrm{ml}$ of saline solution into the uterine cavity followed by transvaginal ultrasound scan that might help diagnose an intrauterine mass. ${ }^{11}$

The aim of the study was to determine the histopathological pattern of endometrial biopsies in perimenopausal women with AUB in a tertiary care hospital in Kerala and to evaluate their treatment outcomes.

\section{Aim and objectives}

The aim of the study were (a) to determine the histopathological pattern of endometrial currettings and/or endometrial biopsies in perimenopausal women with AUB; and (b) to evaluate their treatment outcomes.

\section{METHODS}

The prospective observational study was conducted at the department of obstetrics and gynaecology at Sree Gokulam Medical College and Research Foundation, Venjaramood, Trivandrum, Kerala for a period of one year from December 2019 to December 2020.

The study was conducted on 116 perimenopausal women 41-52 years who presented with AUB and had undergone endometrial sampling with either $\mathrm{D}$ and $\mathrm{C}$ or outpatient endometrial biopsy with EZE curette.

These ladies were subsequently followed up for six months post procedure to assess the response to medical treatment or need for any surgical intervention like hysterectomy.

\section{Criteria}

Patients with AUB between 41 to 52 years who presented to obstetrics and gynecology OPD were included in our study. Patients with inadequate sample were excluded.

\section{RESULTS}

A total of 116 perimenopausal women underwent D and C or endometrial biopsy in this study period and samples were submitted for histopathological examination.

From the Table 2 it was seen that about $39.65 \%$ patients had heavy and prolonged menstrual bleeding and $18.16 \%$ patients had irregular bleeding. $14.65 \%$ patients had prolonged flow, $8.6 \%$ had heavy flow, $6.8 \%$ had infrequent with prolonged flow, $6 \%$ had prolonged, infrequent with heavy bleeding.

From the Table 3 it was seen that non-structural causes contributed to about $60.4 \%$ of AUB in perimenopausal women and $39.6 \%$ had structural causes.

From the Table 4 it was seen that $49 \%$ cases were secretory endometrium. $29.31 \%$ had disordered proliferative endometrium, $4.3 \%$ had proliferative endometrium, $5.2 \%$ each had polyp or hyperplasia without atypia, $2.58 \%$ each had well differentiated adenocarcinoma or atrophic endometrium.

From Table 5, it was seen that $18(15.5 \%)$ cases underwent hysterectomy, 3 patients who had adenocarcinoma underwent staging laparotomy, 2 patients had LNG IUS (Levonorgestrel intrauterine system) insertion and 93 patients were on follow up with no treatment (40 patients) or given antifibrinolytics or hormonal therapy (53 patients).

Of the 18 hysterectomies, 6 patients had endometrial hyperplasia without atypia and opted for hysterectomy, 8 patients had failed medical therapy and 4 patients had associated leiomyoma.

Table 2: Patterns of menstrual bleeding.

\begin{tabular}{|lll|}
\hline Patterns of bleeding & $\begin{array}{l}\text { Number of } \\
\text { patients }\end{array}$ & $\begin{array}{l}\text { Percentage } \\
(\%)\end{array}$ \\
\hline $\begin{array}{l}\text { Frequent bleeding }(<\mathbf{2 4} \\
\text { days cycle) }\end{array}$ & 4 & 3.5 \\
\hline $\begin{array}{l}\text { Infrequent bleeding } \\
\text { (>38 days) }\end{array}$ & 2 & 1.72 \\
\hline $\begin{array}{l}\text { Prolonged flow (>8 } \\
\text { days) }\end{array}$ & 17 & 14.65 \\
\hline Irregular bleeding & 22 & 18.16 \\
\hline Heavy flow & 10 & 8.62 \\
\hline $\begin{array}{l}\text { Infrequent + prolonged } \\
\text { bleeding }\end{array}$ & 8 & 6.89 \\
\hline $\begin{array}{l}\text { Infrequent + prolonged } \\
\text { + heavy flow }\end{array}$ & 7 & 6.03 \\
\hline $\begin{array}{l}\text { Heavy + prolonged } \\
\text { flow }\end{array}$ & 46 & 39.65 \\
\hline Total & 116 & 100 \\
\hline
\end{tabular}

Table 3: Structural and non-structural causes.

\begin{tabular}{|lll|}
\hline Etiology of AUB & $\begin{array}{l}\text { Number of } \\
\text { patients }\end{array}$ & $\begin{array}{l}\text { Percentage } \\
(\%)\end{array}$ \\
\hline $\begin{array}{l}\text { Structural causes } \\
\text { (PALM) }\end{array}$ & 46 & 39.6 \\
\hline $\begin{array}{l}\text { Non-structural causes } \\
\text { (COEIN) }\end{array}$ & 70 & 60.4 \\
\hline Total & 116 & 100 \\
\hline
\end{tabular}


Table 4: Histopathological patterns of endometrium.

\begin{tabular}{|lll|}
\hline Histological patterns & $\begin{array}{l}\text { Number of } \\
\text { patients }\end{array}$ & $\begin{array}{l}\text { Percentage } \\
(\%)\end{array}$ \\
\hline $\begin{array}{l}\text { Secretory } \\
\text { endometrium }\end{array}$ & 57 & 49 \\
\hline $\begin{array}{l}\text { Disordered } \\
\text { proliferative } \\
\text { endometrium }\end{array}$ & 34 & 29.31 \\
\hline $\begin{array}{l}\text { Proliferative } \\
\text { endometrium }\end{array}$ & 5 & 4.31 \\
\hline Polyp & 6 & 5.2 \\
\hline Atrophic & 3 & 2.58 \\
\hline $\begin{array}{l}\text { Well differentiated } \\
\text { adeno carcinoma }\end{array}$ & 3 & 2.58 \\
\hline Decidualised & 2 & 1.72 \\
\hline $\begin{array}{l}\text { Hyperplasia without } \\
\text { atypia }\end{array}$ & 6 & 5.2 \\
\hline Total & 116 & 100 \\
\hline
\end{tabular}

Table 5: Management outcomes.

\begin{tabular}{|lll|}
\hline Management outcomes & $\begin{array}{l}\text { Number of } \\
\text { patients }\end{array}$ & $\begin{array}{l}\text { Percentage } \\
(\%)\end{array}$ \\
\hline Hysterectomy & 18 & 15.5 \\
\hline Staging laparotomy & 3 & 2.5 \\
\hline LNG IUS & 2 & 1.8 \\
\hline Medical management & 53 & 45.68 \\
\hline No treatment & 40 & 34.48 \\
\hline Total & 116 & 100 \\
\hline
\end{tabular}

\section{DISCUSSION}

Evaluation of AUB in perimenopausal age is an important step since excessive or continuous bleeding may severely compromise the quality of woman's life and daily activities leading to anaemia if left untreated. AUB may be the reflection of serious underlying pathologies. In perimenopausal women, AUB presents in different menstrual patterns like heavy menstrual bleeding, frequent menstrual cycles, intermenstrual bleeding and amenorrhea followed by continuous heavy bleeding.

In the present study 116 patients with AUB from 41-52 years were included and these women were subjected to either dilatation and curettage or office endometrial aspiration with Eze curette. These patients were followed up for six months post procedure.

$\mathrm{D}$ and $\mathrm{C}$ is a useful and cost-effective method of detecting intrauterine lesions. It is a diagnostic as well as a therapeutic procedure. The sensitivity of endometrial aspiration for detection of endometrial abnormalities has been reported to be as high as $96 \%$ with $2-6 \%$ false negative rates. Hysteroscopy guided biopsy is the gold standard method for screening as well as diagnostic purposes. ${ }^{12}$ In this present study most of the women $(39.6 \%)$ presented with heavy menstrual bleeding (HMB) followed by irregular bleeding $(18.16 \%)$. In the study by
Kalambe et al $48.4 \%$ patients had HMB ,35.83\% patients had irregular bleeding. ${ }^{13}$ In Gupta et al study, commonest symptoms were heavy menstrual bleeding $(72 \%)$ followed by heavy and frequent bleeding. ${ }^{14}$ Sreelekshmi et al reported $83.7 \%$ heavy menstrual bleeding, frequent menstrual bleeding (26.6\%) and intermenstrual bleeding (4\%). ${ }^{12}$ In the study done by Archana Singh et al, HMB contributed to $67.58 \%$ of cases. ${ }^{15}$ In all these studies and our study, HMB (heavy + prolonged menstrual flow) contributed to the highest percentage of cases.

In our study PALM structural causes contributed to $39.6 \%$ cases and COEIN functional causes $60.4 \%$ cases. In Tukaram et al study functional causes contributed to 41 (55\%) of cases and organic lesions contributed to 33 (45\%) of cases. ${ }^{16}$ In the study conducted by Singh et al PALM and COEIN accounted for $60 \%$ and $39.9 \%$ respectively unlike our study. ${ }^{15}$ In the study conducted by Kalambe et al PALM contributed to $57.5 \%$ and COEIN to $42.5 \%$ cases. ${ }^{13}$

The present study showed secretory endometrium in $49 \%$ of cases followed by disordered proliferative endometrium in $29.31 \%$, polyp and non-atypical endometrial hyperplasia in $5.17 \%$, proliferative endometrium $4.31 \%$. In Sreelakshmi et al study proliferative endometrium contributed to $30.3 \%$, secretory endometrium was $27.4 \%$ and disordered proliferative endometrium $6.6 \%{ }^{12}$ In the study by Vani et al $30.3 \%$ cases were proliferative endometrium, $25.97 \%$ were secretory endometrium and $5.62 \%$ were disordered proliferative endometrium. ${ }^{17}$

\section{Disordered proliferative endometrium}

Abnormal proliferative endometrium with architectural changes due to persistent unopposed estrogen stimulation. Generally taken as benign, not precancerous. It is the continuum of the spectrum of changes seen with persistent, unopposed estrogen stimulation, which can lead to hyperplasia without atypia. There is presence of irregularly shaped or cystic dilated glands with relatively normal gland to stroma ratio. Common in patients with polycystic ovary syndrome, obesity and perimenopausal women and is associated with anovulation. It may be asymptomatic or presents with abnormal uterine bleeding. It is diagnosed with endometrial biopsy or curettage. Ultrasound may show irregularly thickened endometrium. Treatment is observation or progesterone if symptomatic AUB or elimination of the cause of estrogen excess (eg: weight loss in obesity). Endometrial hyperplasia without atypia is a continuum with disordered proliferative endometrium. Here, the gland to stroma ratio is $>1 .^{18}$

\section{Endometrial hyperplasia (EH)}

Proliferation of endometrial glands with resulting increase in gland to stroma ratio. Current classification system includes: hyperplasia without atypia and atypical hyperplasia/endometrial intraepithelial neoplasia (AH/EIN). $\quad \mathrm{AH} / \mathrm{EIN}$ is considered a premalignant condition. It has increased risk of both progression to and 
simultaneous endometrial endometrioid adenocarcinoma. Endometrial hyperplasia occurs due to unopposed estrogen. Treatment of EH without atypia includes progestin therapy oral or intrauterine device. Hysterectomy is an aggressive management as risk of progression to adenocarcinoma is low. Definitive treatment of $\mathrm{AH}$ includes hysterectomy with or without bilateral salpingo-oophorectomy. If patient desires fertility oral progestin can be given. ${ }^{19}$

In our study, 18 (15.5\%) patients underwent hysterectomy, $45.68 \%$ (53) patients took medical management, 2 patients had LNG IUCD insertion. In the study by Sreelakshmi et al $69.6 \%$ underwent hysterectomy.

\section{CONCLUSION}

In our study, 116 perimenopausal women with AUB 4152 years underwent endometrial sampling. Heavy menstrual bleeding was the most common presenting symptom. The functional cause COEIN contributed to about $60 \%$ of cases. On evaluating the endometrium, secretory endometrium was commonest (49\%) followed by disordered proliferative endometrium (29.3\%). On follow up for six months, $15.5 \%$ patients underwent hysterectomy, 2 patients had insertion of levonorgestrel IUD, $45.68 \%$ patients had medical management with antifibrinolytics or hormones and is on follow up. The responsibility of gynaecologist in the management of AUB in perimenopausal women is to exclude hyperplasia of endometrium and endometrial cancer.

\section{ACKNOWLEDGMENTS}

We are indebted to Dr. Neelima V. Nair, Dr. Divya R. Prasad, Dr. Kala Renjini, Sree Gokulam Medical College and Research Foundation, Venjaramood, Thiruvananthapuram for their valuable inputs and support.

\section{Funding: No funding sources}

Conflict of interest: None declared

Ethical approval: Not required

\section{REFERENCES}

1. Liu Z, Doan QV, Blumenthal P, Dubois RW. A systematic review evaluating health-related quality of life, work impairment, and health-care costs and utilization in abnormal uterine bleeding. Value Health. 2007;10(3):183-94.

2. Oehler MK, Rees MC. Menorrhagia: an update. Acta Obstet Gynecol Scand. 2003;82(5):405-22.

3. Munro MG, Critchley HOD, Fraser IS, FIGO Menstrual Disorders Committee. The two FIGO systems for normal and abnormal uterine bleeding symptoms and classification of causes of abnormal uterine bleeding in the reproductive years: 2018 revisions. Int J Gynaecol Obstet. 2018;143(3):393408 .
4. NICE. Heavy menstrual bleeding: Assessment and management (NG 88), 2018. Available at: https://www.nice.org.uk/guidance/ng88. Accessed on 02 June 2021.

5. WHO Scientific Group on Research on the Menopause in the 1990. Research on the menopause in the 1990s: report of a WHO scientific group, 2020. Available at: https://apps.who.int/iris/handle/10665/41. Accessed on 02 June 2021.

6. Mishra D, Sultan S. FIGO's PALM-COEIN Classification of Abnormal Uterine Bleeding: A Clinico-histopathological Correlation in Indian Setting. J Obstet Gynaecol India. 2017;67(2):119-25.

7. Vercellini P, Cortesi I, Oldani S, Moschetta M, Giorgi $\mathrm{O}$, Crosignani PG. The role of transvaginal ultrasonography and outpatient diagnostic hysteroscopy in the evaluation of patients with menorrhagia. Hum Reprod. 1997;12(8):1768-71.

8. Ash SJ, Farrell SA, Flowerdew G. Endometrial biopsy in DUB. J Reprod Med. 1996;41(12):892-6.

9. National Collaborating Centre for Women's and Children's Health (UK). Heavy Menstrual Bleeding. London: RCOG Press; 2007.

10. Seamark CJ. The demise of the D\&C. J R Soc Med. 1998;91(2):76-9.

11. Telner DE, Jakubovicz D. Approach to diagnosis and management of abnormal uterine bleeding. Can Fam Physician. 2007;53(1):58-64.

12. Sreelakshmi U, Bindu VT, Subhashini T. Abnormal Uterine Bleeding in perimenopausal age group women: a study on clinicopathological evaluation and management. Int $\mathbf{J}$ Reprod Contracept Obstet Gynecol. 2018;7:192-7.

13. Kalambe M, Jungari M, Chaudhary A, Kalambe A, Shrivastava D. Palm Coein Figo Classification System for Causes of Abnormal Uterine Bleeding (AUB) in Non Gravid Women of Reproductive Age Group in a Peri Urban Tertiary Care Hospital. Int $\mathbf{J}$ Curr Res Rev. 2018;12(15):128-33.

14. Gupta A, Rathore AM, Manaktala U, Rudingwa P. Evaluation and histopathological correlation of abnormal uterine bleeding in perimenopausal women. Int J Biomed Advance Res. 2013;4(8):509.

15. Singh A, Choudhary A. A Study of PALM-COEIN Classification of Abnormal Uterine Bleeding (AUB) in Perimenopausal Women at a Tertiary Care Teaching Hospital. J Med Sci Clinic Res. 2018; 6(6):287-92.

16. Chitra T, Manjani S, Madhumittha R. Histopathology of endometrial curettings in perimenopausal women with abnormal uterine bleeding. J Evolution Med Dent Sci. 2016;5(24):1285-90.

17. Vani BS, Vani R, Jijiya BP. Histopathological evaluation of endometrial biopsies and curettings in abnormal uterine bleeding. Trop J Path Micro. 2019;5(4):190-7.

18. Chang R, Chen H. Disordered proliferative, 2021. Available at: https://www.pathology out-lines 
.com/topic/uterusdisordered proliferative. Accessed on 02 June 2021.

19. Sharma A, Lastra RR. Endometrial hyperplasia, 2021. Available at: https://www.pathologyoutlines.com /topic/uterusendometrialhyperplasiageneral.HTML. Accessed on 02 June 2021.
Cite this article as: Nair BL, Kuriakose LS. Histopathological evaluation of endometrial sampling in perimenopausal women with abnormal uterine bleeding. Int J Reprod Contracept Obstet Gynecol 2021;10:3180-5. 